\title{
Actualidades de la legislación mexicana sobre el uso de datos personales en la atención médica y la confidencialidad como derecho del médico
}

\author{
César Francisco Contreras-López \\ Universidad Autónoma de Baja California, Facultad de Medicina, Mexicali, Baja California, México
}

\begin{abstract}
Resumen
Recientemente se han publicado nuevas leyes sobre el manejo de datos personales. Los médicos deben conocerlas toda vez que la información que obtienen del paciente ha quedado sujeta a lo establecido en ellas. Para armonizar la actividad médica con estas disposiciones es necesario revisar el marco legal actual. Después de este análisis observamos que no se incluyen los datos que el médico anota en el expediente clínico en forma de opiniones u observaciones técnicas dirigidas a otros profesionales de la salud. Consideramos que se debe proteger esta información igual que la del paciente, con el fin de dar certeza legal al derecho del médico a la discrecionalidad y confidencialidad establecidas en la "libertad prescriptiva".
\end{abstract}

PALABRAS CLAVE: Datos personales. Marco legal. Protección de la información.

\begin{abstract}
Recently, new laws on the handling of personal data have been published. Physicians should know them, since the information they obtain from the patient has been subject to what is therein established. To harmonize medical activity with these provisions, it is necessary to review the current legal framework. After this analysis, we observed that data the doctor registers in the medical record in the form of opinions or technical observations directed to other health professionals are not included. We consider this information should be protected the same way as that of the patient, in order to give legal certainty to the right of doctors to the discretion and confidentiality established in the "prescriptive freedom".
\end{abstract}

KEY WORDS: Personal data. Legal framework. Information protection.

\section{Antecedentes}

La secrecía en el manejo de la información que obtiene el médico durante el desarrollo del acto médico presupone la obligación de mantener ciertos datos y en ciertas circunstancias bajo buen resguardo, impidiendo su divulgación que pudiera causar un menoscabo en la integridad personal, social, religiosa, etcétera, del paciente.

El principio anterior no es nuevo para el médico. Desde el punto de vista deontológico, existen documentos como el Juramento de Hipócrates, los Consejos de Esculapio y el Código Internacional de Ética Médica en los que se establece la obligación de mantener bajo absoluto secreto la información confiada por los pacientes como un principio ético básico en el ejercicio de la profesión.

En cuanto a las normas jurídicas, desde el siglo pasado en el Código Penal existe el delito de "revelación de secreto" que obliga a la confidencialidad en el manejo de la información, sobre todo cuando la responsabilidad de la secrecía se adquiere como profesional o servidor público (artículos 210 y 211 del Código Penal
Correspondencia:

César Francisco Contreras-López

E-mail: drcesarcontreras@outlook.com
Fecha de recepción: 06-07-2017

Fecha de aceptación: 13-02-2018

DOI: 10.24875/GMM.18003547
Gac Med Mex. 2018;154:693-697

Disponible en PubMed www.gacetamedicademexico.com 
Federal vigente). Por su parte, la Ley Reglamentaria del artículo 5 constitucional relativo al ejercicio de las profesiones en el Distrito Federal, impone al profesional la obligación de "guardar estrictamente el secreto de los asuntos que se le confieren por sus clientes" (artículo 36). Similares disposiciones se encontraban en la NOM 168 del expediente clínico (numeral 5.6) y en la NOM 190 criterios para la atención médica de la violencia intrafamiliar (numeral 5.7), recientemente sustituidas por la NOM-004 y la NOM 046, respectivamente.

Como parte de la segunda reforma que se realizó al artículo 6 de nuestra Constitución en 2007, en esta se da un sentido más claro al "derecho de acceso a la información", sentando las bases para el ejercicio pleno de esta garantía y obligando al Estado a poner a disposición de cualquier ciudadano clara y oportunamente la información en posesión de cualquier ente del gobierno. Sin embargo, cuando se trata de información producto de la atención médica, continúa la protección en el uso que se le da porque se considera parte de la vida privada de las personas (actualmente artículo 6, apartado A, fracción II de la Constitución Política).

La protección, acceso, rectificación y cancelación del uso de datos personales adquirió el carácter de derecho humano fundamental al modificarse en 2009 el artículo 16 de la Constitución.

\section{Definición de conceptos}

Es necesario recordar ciertas definiciones con el fin de ubicar el contexto al hablar de protección de la información que el paciente entrega y la que el médico produce durante la atención médica.

Por datos personales se entiende cualquier información concerniente a una persona física identificada o identificable (artículo 3, fracción V de la Ley Federal de Protección de Datos Personales en Posesión de los Particulares); en esta definición se incluyen el nombre, apellido, domicilio, correo electrónico y también los que tienen una mayor relación con la intimidad de su titular. ${ }^{1}$

Por datos personales sensibles se entiende: ${ }^{2}$

Aquellos datos personales que afecten a la esfera más íntima de su titular, o cuya utilización indebida puede dar origen a discriminación o conlleve un riesgo grave para este. En particular, se consideran sensibles aquellos que puedan revelar aspectos como origen racial o étnico, estado de salud presente y futuro, información genética, creencias religiosas, filosóficas y morales, afiliación sindical, opiniones políticas, preferencia sexual.

La libertad prescriptiva del médico es un principio científico y ético que tiene la finalidad de orientar la práctica de la profesión médica, otorgando a los profesionales, técnicos y sus auxiliares de las disciplinas para la salud discrecionalidad en su actuar. La libertad prescriptiva debe ejercerse en aras de obtener el beneficio del paciente y en ninguna circunstancia debe equipararse con la arbitrariedad, pues el actuar del personal médico debe fundamentarse en el estado actual de la ciencia médica y encaminarse en todo momento al beneficio del paciente, tomando en consideración las circunstancias de cada caso. ${ }^{3}$

La confidencialidad consiste en guardar reserva sobre las informaciones que afectan la vida privada de los individuos. Toda persona tiene derecho a que se respete el carácter confidencial de los datos referentes a su salud, ya que nadie puede acceder a ellos sin previa autorización amparada por la ley. ${ }^{4}$

\section{Disposiciones legales para el manejo de datos personales aplicables al personal de salud}

\section{Constitución Política de los Estados Unidos Mexicanos}

El derecho a la información fue integrado en el artículo 6 de nuestra Constitución en $1977 .{ }^{5}$ Posteriormente, en julio de 2007 se agregaron a este artículo los principios y bases para el ejercicio del derecho de acceso a la información como apartado A con siete fracciones, de las cuales nos interesa especialmente la fracción II en la que se menciona: "la información que se refiere a la vida privada y los datos personales será protegida en los términos y con las excepciones que fijen las leyes". ${ }^{6}$ Estos dos antecedentes se pueden considerar como el paso más firme en México hacia la búsqueda del derecho a proteger la información personal en privado. A nivel constitucional, el siguiente paso se dio en 2009 al agregar en el artículo 16 lo siguiente: "toda persona tiene derecho a la protección de sus datos personales, al acceso, rectificación y cancelación de los mismos, así como a manifestar su oposición..."

\section{Ley de Transparencia y Acceso a la Información Pública Gubernamental}

En esta primera ley específica, publicada en 2002, se garantizaba el acceso de toda persona a la información en posesión de los Poderes de la Unión, los órganos constitucionales autónomos o con autonomía legal, y cualquier otra entidad federal. Esta ley fue dejada sin vigor y sustituida en 2016. 


\section{Ley Federal de Protección de Datos Personales en Posesión de los Particulares}

Publicada como nueva ley el 5 de julio de 2010, su objetivo es:

La protección de los datos personales en posesión de los particulares, con la finalidad de regular su tratamiento legítimo, controlado e informado, a efecto de garantizar la privacidad y el derecho a la autodeterminación informativa de las personas.

Como su nombre lo indica, es aplicable cuando el uso de datos personales se realice por particulares. En la prestación de servicios de salud se aplica en quienes realizan actividades en el medio privado en lugares como consultorios de medicina general o de especialidad, clínicas, hospitales, laboratorios, farmacias, etcétera. Entre los conceptos más importantes por resaltar en esta ley podemos mencionar los siguientes:

- La obtención de datos personales no debe hacerse a través del engaño o fraude.

- El tratamiento de datos personales estará sujeto al consentimiento del titular (la persona física a quien corresponden los datos personales) y que este será expreso cuando se haga verbalmente, por escrito, por medios electrónicos, etcétera, o tácito cuando el titular no manifieste oposición al ponerle a la vista el aviso de privacidad.

- Cuando se trata de datos personales sensibles, el responsable (persona que decide sobre el tratamiento de los datos personales) deberá obtener el consentimiento expreso y por escrito del titular a través de su firma autógrafa o electrónica.

- Los datos personales sensibles no requieren el consentimiento anterior cuando sean indispensables para la atención médica, prevención, diagnóstico, tratamientos médicos, entre otros.

- Si el responsable pretende tratar los datos para un fin distinto que no se haya establecido en el aviso de privacidad requerirá obtener el consentimiento del titular.

- El aviso de privacidad es el documento impreso, digital, visual, sonoro, etcétera, en el que el responsable informa al titular los fines para los que recaba la información. Si se trata de datos sensibles se deberá expresar que se trata de este tipo de datos.

- El titular tiene derecho a solicitar el acceso, rectificación, cancelación y oposición sobre sus datos personales (derechos ARCO).

\section{Ley General de Transparencia y Acceso a la Información Pública}

Publicada el 4 de mayo de 2015, esta ley sustituye la Ley Federal de Transparencia y Acceso a la Información Pública Gubernamental (2002). Esta es la ley reglamentaria del artículo 6 constitucional. Establece los principios, bases generales y procedimientos para garantizar el derecho de acceso a la información en posesión de los sujetos obligados en cualquier entidad gubernamental que reciba y ejerza recursos públicos o realice actos de autoridad de la federación, los estados y los municipios. Menciona el acceso a la información como un derecho humano.

\section{Ley Federal de Transparencia y Acceso a la Información Pública}

Publicada el 9 de mayo de 2016, tiene por objeto proveer lo necesario en el nivel federal para garantizar el derecho de acceso a la información pública en poder de cualquier entidad gubernamental que reciba y ejerza recursos públicos o realice actos de autoridad de la federación. De acuerdo con esta ley, información confidencial es "...aquella que contiene datos personales concernientes a una persona física identificada o identificable..." y solo podrán tener acceso a ella los titulares de esta, sus representantes y los servidores públicos facultados para ello.

\section{Ley General de Protección de Datos Personales en Posesión de Sujetos Obligados}

Por su parte, esta ley es reglamentaria del apartado A del artículo 6 y del segundo párrafo del artículo 16, ambos de nuestra constitución, para la protección de los datos personales en posesión de sujetos obligados, es decir, se aplica a las personas que realizan sus actividades en el campo de la medicina como empleados del gobierno. Esta es la ley más reciente en esta materia, ya que fue publicada por primera vez en enero de 2017. Entre sus principales disposiciones resaltan:

- El responsable no estará obligado a recabar el consentimiento del titular para el tratamiento de sus datos personales cuando los datos personales se requieran para ejercer un derecho o cumplir obligaciones derivadas de una relación jurídica entre el titular y el responsable (como lo es el acto médico). 
- Lo mismo aplica cuando exista una situación de emergencia que potencialmente pueda dañar a un individuo en su persona y cuando sus datos sean necesarios para efectuar un tratamiento para la prevención, diagnóstico y prestación de asistencia sanitaria.

- A solicitar los derechos ARCO en cualquier momento. Este ejercicio deberá realizarse a través de solicitud en la que se acredite la identidad del titular. En el caso de menores, persona distinta o fallecidos, la persona interesada deberá acreditar la identidad y personalidad con que actúa.

\section{Ley Reglamentaria del Artículo 5 Constitucional, Relativo al Ejercicio de las Profesiones en el Distrito Federal}

Sobre este tema, esta ley en su artículo 36 refiere que "todo profesionista estará obligado a guardar estrictamente el secreto de los asuntos que se le confíen por sus clientes..."

\section{Reglamento de la Ley General de Salud en Materia de Prestación de Servicios de Atención Médica}

Derivado de la Ley General de Salud, el reglamento en materia de atención médica establece en el artículo 29 que "todo profesional de la salud estará obligado a proporcionar al usuario, familiar, tutor o representante legal, información completa sobre el diagnóstico, pronóstico y tratamiento correspondientes". Además, obliga al responsable sanitario a "proporcionar un resumen clínico sobre el diagnóstico, evolución, tratamiento y pronóstico del padecimiento que ameritó el internamiento" (artículo 30).

\section{Norma oficial mexicana NOM-004- SSA3-2012, del expediente clínico}

Esta norma es la que viene a confirmar los criterios de propiedad, titularidad y confidencialidad (entre otros) para el manejo de la información y del expediente clínico propiamente dicho.

En su introducción, la norma señala el reconocimiento de titularidad del paciente sobre los datos que proporciona al personal del área de salud (información que quedará asentada en las notas correspondientes), los cuales son considerados confidenciales, por lo que el personal de salud, atendiendo a los principios éticos que rigen a su profesión, debe mantener en secreto.

También en lo que parece un intento por brindar seguridad al personal del área de la salud sobre las anotaciones que realiza, se brinda protección a los datos personales y se les otorga el carácter de confidencial, sin embargo, no queda claramente establecido si se trata de los datos personales del personal de salud o continúa hablando de los datos personales de los pacientes.

En relación con la propiedad del expediente clínico queda asentado claramente que pertenece al prestador del servicio (5.4). Esta disposición puede generar un conflicto entre médico y paciente, toda vez que debería ser más claro que el derecho de este último alcanza solo para tener acceso a la información contenida dentro del expediente clínico, no a ejercer derechos sobre el propio expediente clínico.

\section{Obligación de revelar el secreto médico o los datos personales}

Existen también ordenamientos legales que en ciertas circunstancias obligan al médico a revelar datos personales $u$ otra información sobre la atención del paciente con el fin de prevenir riesgos a la salud 0 durante los procedimientos que llevan a cabo autoridades judiciales 0 administrativas.

\section{Ley General de Salud}

Esta ley es aplicable en los casos que establecen las leyes anteriores en relación con el tratamiento de datos personales en poder de sujetos obligados y de los particulares, cuando el prestador de servicios de salud (público o privado) considere necesario difundir dicha información para efectos de prevención y control de enfermedades y accidentes, tal como se establece en el capítulo II del título octavo de esta ley referente a las enfermedades transmisibles, ya que el artículo 136 menciona que es obligatoria la notificación a la Secretaría de Salud de enfermedades tales como fiebre amarilla, peste y cólera, las cuales se deben notificar inmediatamente, al igual que las que se presenten en forma de brote o epidemia y en un plazo no mayor de 24 horas como poliomielitis, meningitis meningocócica, influenza viral, sarampión, paludismo, infección por el virus de la inmunodeficiencia, entre otras. 


\section{Norma oficial mexicana NOM-004- SSA3-2012, del expediente clínico}

La norma establece que los datos personales únicamente podrán ser proporcionados a terceros cuando medie la solicitud escrita del paciente (5.5.1), lo anterior podrá ser realizado de forma verbal o escrita en forma de resumen clínico, siempre y cuando sea, a su vez, solicitado por escrito. Cuando así lo solicite una autoridad judicial, órganos de procuración de justicia y autoridades administrativas se deberá entregar el expediente clínico (5.6).

Mención aparte merece la autorización que otorga esta misma norma cuando la divulgación de datos personales sea para efectos de docencia e investigación, en cuyo caso se deberá obtener el consentimiento por escrito del paciente y se deberán adoptar las medidas necesarias para que éste no pueda ser identificado.

\section{Norma oficial mexicana NOM-046- SSA2-2005, violencia familiar, sexual y contra las mujeres, criterios para la prevención y atención}

En esta norma se obliga a los prestadores de servicios médicos que atienden pacientes en esta situación a informar al ministerio público para "los efectos de procuración de justicia a que haya lugar" (5.10) y cada caso se debe notificar a la Secretaría de Salud para la vigilancia epidemiológica correspondiente (5.11).

\section{Código Nacional de Procedimientos Penales}

En este nuevo código, publicado en 2014, el artículo 362 establece que es inadmisible el testimonio de los médicos, psicólogos, enfermeros (entre otros profesionales y servidores públicos) por su deber de guardar secreto de la información que no es susceptible de divulgación de acuerdo con las leyes aplicables, a menos que el interesado los libere de la responsabilidad de ese deber.

\section{Conclusiones}

Después de analizar las nuevas disposiciones federales para el manejo de datos personales, así como las ya existentes, observamos que en ninguna de estas se ha tomado en cuenta la posición de los profesionales y técnicos sanitarios respecto a las anotaciones, que, como parte de su trabajo, realizan en el expediente clínico.

Davara Fernández, en 2012, ya mencionaba la necesidad de desarrollar un marco normativo específico en el que se proteja la propiedad intelectual de los comentarios y opiniones del profesional sanitario, ${ }^{7} \sin$ embargo, en la presente revisión del marco legal solo encontramos un leve acercamiento a esto en la NOM-004.

El acceso al expediente clínico queda fuera del control del personal de salud a pesar de que se le reconoce la propiedad de este, ya que el paciente (o las personas que él designe), así como las autoridades, pueden disponer de la información en cualquier momento y para los fines que consideren pertinentes.

Las anotaciones que en forma de observaciones, apreciaciones, comentarios u opiniones realiza el personal de salud sobre la atención médica son, en gran medida, de tipo subjetivo y por lo tanto responsabilidad de cada persona, por lo que consideramos que es necesario extender la confidencialidad legal de la información para proteger al personal de salud de la intromisión y el uso inadecuado de ciertas anotaciones, para de esta manera garantizar el derecho del médico a la libertad prescriptiva como un principio que orienta a la práctica médica, manteniendo bajo resguardo legal la información que el personal de salud anote en el expediente clínico, sin menoscabo en el derecho del paciente al acceso a su información que otorgan las nuevas leyes en la materia.

\section{Bibliografía}

1. Cano GA. Protección de datos personales en el marco del derecho a la salud y el valor de la confidencialidad en la relación médico-paciente. Mesa de discusión. Memoria Simposio Conamed. 2016;4(4): 237-244.

2. Ley Federal de Protección de Datos Personales en Posesión de los Particulares, artículo 3, fracción VI. Diario Oficial de la Federación 2010 Jul 5.

3. Libertad prescriptiva del médico. Parte integradora del derecho al trabajo de los médicos. Tesis aislada 1a XXII/2013 (10a), primera sala. Décima época. Semanario Judicial de la Federación y su Gaceta, libro XVI, enero de 2013. p. 637. Disponible en: https://sjf.scjn.gob.mx/sjfsist/Documentos/Tesis/2002/2002564.pdf

4. Frigieri AJ. Las historias clínicas. Aspectos jurídicos y el derecho a la reserva de la información. Revista CONAMED. 2014;9(4):19-25.

5. Decreto que reforma y adiciona los artículos $6,41,51,52,53,54,55,60,61$, $65,70,73,74,76,93,97$ y 115 de la Constitución Política de los Estados Unidos Mexicanos. Diario Oficial de la Federación 1977 Dic 6. Disponible en: http://www.dof.gob.mx/nota_detalle.php?codigo=4664439\&fecha=06/12/1977

6. Decreto por el que se adiciona un segundo párrafo con siete fracciones al Artículo 6o. de la Constitución Política de los Estados Unidos Mexicanos. Diario Oficial de la Federación 2207 Jul 20. Disponible en: http://www. dof.gob.mx/nota_detalle.php?codigo=4994148\&fecha=20/07/2007

7. Fernández ID. Breve aproximación a las implicaciones jurídicas y operativas del tratamiento de datos de salud. Gaceta Médica de México. 2012; 148:480-6. 